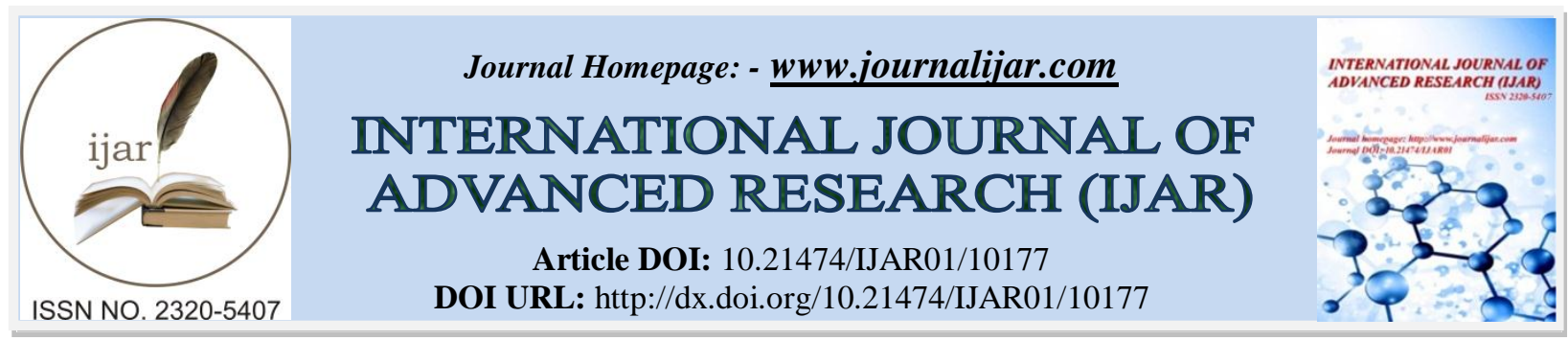

RESEARCH ARTICLE

\title{
DIORAMA OF TRIBAL CRAFTS MARKET : WITH SPECIAL REFERENCE TO BASTAR
}

\section{Srishti Hemant ${ }^{1}$ and Dr. Ashok Pawar ${ }^{2}$}

1. Research Scholar, Faculty of Marketing Management, Smt.Hiraben Nanavati Institute of Management and Research for Women.

2. Associate Professor(H.O.D), Faculty of Marketing Management, Smt. Hiraben Nanavati Institute of Management and Research for Women ,Pune,India.

\section{Manuscript Info}

\section{Manuscript History}

Received: 05 October 2019

Final Accepted: 07 November 2019

Published: December 2019

Key words:-

Marketing Methods, Bastar Arts, Tribal

Craft, Barriers In Marketing

\begin{abstract}
The tribal craft works that are a reflection of tradition, cultures and social values and are the major elements contributing in glorification of our country. The tribal art of Bastar district of Chhattisgarh is one of the oldest and exclusive art form that belongs to the period of Mohenjodaro and Harrappa. This segment of artistry provides employment to various tribal artisans from Bastar. The brilliance in creation and fine finishing of these art pieces are a reflection of mastery in carving possessed by the craftsmen. These art works are exceptional medium of representing the culture of these tribals. Presently very few categories of such art works are available in domestic and international markets. These art works are available in wide range of products such as items of daily utility, gift items, home décor items, functional items , and items for religious purpose. This research paper aims to provide a picture of these tribal art forms and its market. This paper also highlights various opportunities that exist in market for these art works , it also focuses upon the barriers in marketing of these products. Analysis of present state of these crafts is also provided in it. Further this paper consists of four segments the first segment highlights about Bastar Arts and its contribution towards growth and development. The next segment stresses upon barriers related to these products. The third segment deals with the initiatives adopted by government for these art works followed by the SWOT analysis of these tribal crafts. The last segment stresses upon the widely adopted marketing methods for these crafts followed by conclusion and suggestion that provides information about the further scope for these art works and the necessity to incorporate appropriate changes in order to achieve long term sustenance.

Copy Right, IJAR, 2019,. All rights reserved.
\end{abstract}

Corresponding Author:- Srishti Hemant

Address:- Research Scholar, Faculty of Marketing Management, Smt.Hiraben Nanavati Institute of Management and Research for Women. 


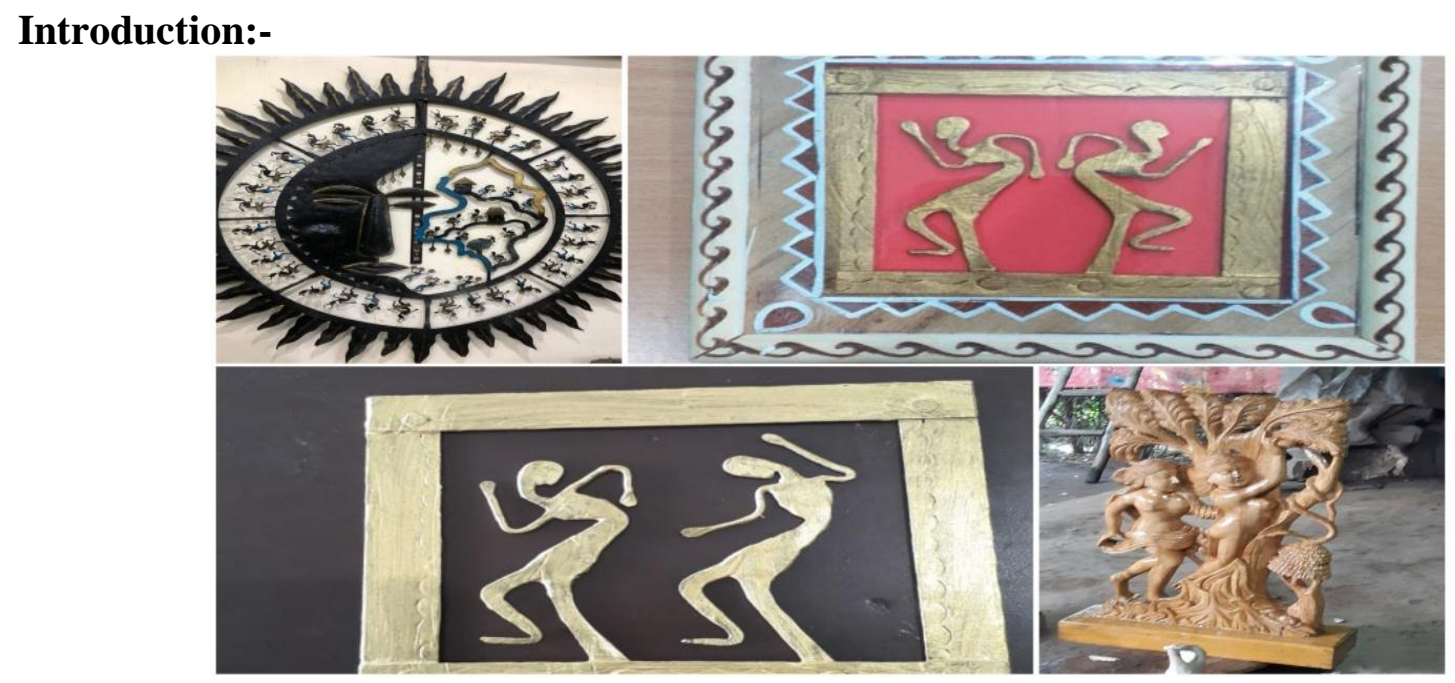

Bastar art majorly revolves around Dhokra art, Wrought Iron art, Terracotta art, Wooden art and Sisal art, amongst these art forms Dhokra art is one of the oldest art form which is presently being practiced in India. Dhokra art is also known as Bell Metal art form in which the art pieces are generated using the lost wax technique which is the most ancient method of preparation of artifacts that includes utilization of wax from beehive for generation of metal which is then heated and transformed into the desired artifact. In case of the Wrought Iron products the minerals of iron ore are collected from the near by mountains and then this ore is transformed into iron and further beaten via tools such as anvil to generate wrought iron which is then shaped according to the desired artifact. Lush green and dense forests of Bastar region of Chhattisgarh are a source of raw material for the wooden artisans, these forests are rich in 'sagon' and 'sivna' woods that are mostly utilized by the wooden artisans to practice their art, these craftsmen firstly develop a blueprint and then carve the required designs.

Riverbeds surrounding Bastar region are the source of raw material for the terracotta artisans, they utilize the clay from these riverbeds and then mix it with soil and then heat the mixture to develop the desired artifact. Lastly the threads of sisal are obtained from the plant named as "Ranbas" which is found in this region, the leaves of these plants are processed to obtain threads of sisal or the sisal fiber which is then knitted as per the desired artifact. All these art forms are unique and are a reflection of high level of creativity of these craftsmen. Despite of conducting practices in poor working conditions their creations are magnificent. Every year these artisans come up with variety of products in a very wide range but are incapable to generate the desired response for their products. The remains from Mohenjodaro are the proof of excellence of these art works that is still being followed and practiced by these artisans. The tribal craft segment of our country plays a vital role in reflecting our age old customs and culture. There is a huge potential for these art works in the world wide market. Due to its distinctiveness and quality it has the potential to grab more and more consumers especially art aficionados. There is an escalating demand for these products in countries such as Itlay, Germany, Switzerland and France etc, which makes these craft works one of the vital factors for attaining foreign currencies. There is a necessity to improvise the process of marketing for these art works. Since, this market is unorganized the artisans don't earn sufficient wages . It is desirable for Government to take necessary steps for promoting these art pieces by increasing exposure via participation in trade fairs and exhibitions in international and domestic levels. The artisans should be encouraged to participate in craft bazaars, haats and there should be involvement of NGO's in providing more and more opportunities to these craftsmen for displaying their skills. These products are not receiving the attention that is desired.

The performance of this sector in terms of marketing and finance is not that satisfactory. This is the second largest segment after agriculture in terms of employment generation with high participation of the weaker segment and also in generation of eco friendly artifacts. This section of rural artisans is highly important for our country's economy. Ample amount of art works are being generated annually but due to insufficient knowledge about technology and due to lacking market and technical knowledge these products are unable to compete with the machine made alternatives available in the market. They are unaware of implementing modern techniques in packaging , scheduling and delivering the products. Various invisible markets under this segment could be identified with the help of coordinated pattern of conducting trade. The emerging forms of media could be highly beneficial in 
popularizing these products and increase the sales of these products. This would enable the consumers to access these products easily and as a result it would generate more brand awareness. Successful web based programs of marketing could be generated if government provides necessary support for promoting these products via emerging forms of media. The consumption pattern of various segments of Bastar Art products is indicated below:

Fig 1:- Representation of current consumption pattern of Bastar Art products as per data obtained from TRIFED.

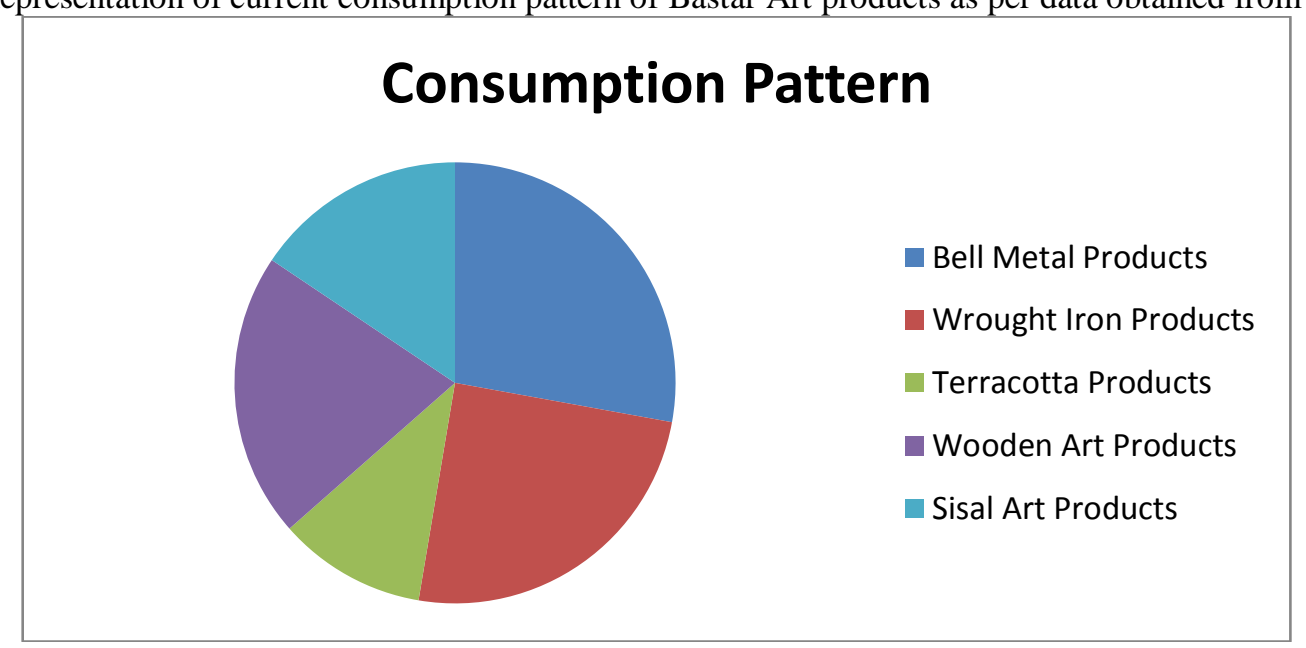

\section{Issues:}

1. Availability of credit is one of the prime factor of concern.

2. Problems associated with non availability of raw materials for certain art forms such as wrought iron art, wooden art and bell metal art.

3. Lack of skilled labor in the market for producing these art works.

4. Problems associated with marketing and designing of these art works.

5. Complications in the existing distribution channel caused by the presence of intermediaries.

6. Overly dependent upon the developed markets.

7. Illiteracy of artisans and lack of promotional efforts.

\section{Objective of the study:-}

To study the current scenario of Tribal Art Market of Bastar .

\section{Research Methodology:-}

This research paper is based on exploratory research. The data utilized in this research paper was collected via various secondary sources.

\section{Barriers in marketing of Tribal Art Products: \\ Do not have Brand Image:}

One of the most important factors influencing the consumers for buying products is the Brand Image, but in case of tribal artifacts there isn't any specific brand name for these products as it is a segment which is unorganized. Various craftsmen are indulged in generation of artifacts in their area of residence. There isn't any homogeneity in terms of brands of these art works and that's the reason why these art forms have to face penetration problem in the market.

\section{Lower Price:}

The larger segment has its own specified norms related to the pricing of these art works but these tribal art works don't have any criteria related to the pricing and the prices of these art works are entirely dependent upon the bargaining power of the consumer 


\section{Sales based upon credits:}

The producers of these art works sell their produce on the basis of credit because retailers do not provide cash on delivery because of decreased market demand for these products. So the producers of these art works are unable to provide a quality art piece since they have to lend money from lenders at high rate of interest that adversely impacts the production of these craft works.

\section{Quality of Craftworks:}

This segment is one of the highly unorganized segments and the craftsmen belonging to this segment are expanded from rural to urban regions. Due to lack of alternatives, conditions of environment and reduction of skilled craftsmen the working conditions of these craftsmen was observed to be different. So, its highly difficult to maintain premium quality of these art works and there is no particular method of assessing the quality of these art works .

\section{Raw Material:-}

The non availability of raw material cerates hindrance in generation of these artifacts. Accessibility to good quality raw material is vital in order to develop art pieces with fine finishing via the process of generation. But some of the segments of Bastar art products are highly impacted with the non availability of raw material such as the wooden artisans who are not allowed to access wood due to increasing concerns for environment also the Wrought Iron artisans have to suffer due to non availability of sufficient mineral in their area. So these craftsmen utilize recycled materials for generating artifacts and hence as a result generate low quality output.

\section{International Transactions:}

One of the prime factors in exporting these art works is the international transactions because exporters earn very low profit due to the decrease in value of rupees in the global market.

\section{Initiatives by government:}

As these craft works play a vital role in our economy, so the government has developed some regulations and policies for proper functioning of this segment:

1. No restrictions have been imposed upon the location for setting up of production unit.

2. The artisans are exempted form possessing license of manufacturing.

3. The owners of center are desired to file IEM i.e. Industrial Entrepreneur Memoranda.

4. The support and service plan has been adopted for the market in order to create awareness of these art works amongst customers and also for extending support in financial terms to the state for initiating more shops.

5. Adoption of plan for Research and Development for assessing opinions on social, artistic and encouragement factors of art works.

6. The plan for training which targets in achieving development of competence levels.

7. For elevating the opportunities in this segment special projects have been undertaken for training for skill development.

8. Scheme for elevating participation of artisans has been implemented.

9. Plan for promotion of special item such as rugs has been implemented.

10. Scheme for providing insurance to the artisans between the 18 to 60 years.

\section{SWOT Analysis:}

\begin{tabular}{|l|l|}
\hline $\begin{array}{l}\text { Sr. } \\
\text { No. }\end{array}$ & Particulars \\
\hline Strengths \\
\hline 1. & Available in wide range due to expanded culture. \\
\hline 2. & Widely spread retail infrastructure. \\
\hline 3. & Huge and wide spread market. \\
\hline 4. & Low cost labor. \\
\hline 5. & Flexibility in production. \\
\hline 6. & Low obstructions of new entrants. \\
\hline 7. & Requires less investment of capital. \\
\hline Weaknesses \\
\hline 1. & Lack facilities of communication. \\
\hline
\end{tabular}




\begin{tabular}{|l|l|}
\hline 2. & Improper working conditions. \\
\hline 3. & Lack of information amongst the artisans about marketing of products. \\
\hline 4. & Illiteracy of the craftsmen. \\
\hline 5. & Un awareness about the current technological advancements. \\
\hline 6. & Lacking systematization between the private and government dealers. \\
\hline 7. & Non availability of skilled labor. \\
\hline 8. & Concentrated in rural regions. \\
\hline 9. & Lack proper promotion. \\
\hline 10. & Non participation of younger generation in production. \\
\hline Opportunities \\
\hline 1. & $\begin{array}{l}\text { Development of segments that require these products such as construction segment , interior } \\
\text { designing, real estate etc. }\end{array}$ \\
\hline 2. & Emerging mediums of digital marketing such as e commerce. \\
\hline 3. & Advancements in tourism segment in domestic and global level. \\
\hline 4. & Advancements in fashion industry. \\
\hline 5. & Elevated demand for these art works from countries such as Italy, Paris, Germany etc. \\
\hline Threats \\
\hline 1. & Elevating competition in the domestic market. \\
\hline 2. & Equity between elevated demand and supply. \\
\hline 3. & Quality art works offered by other countries. \\
\hline 4. & Superior terms of trade proposed by competitive nations. \\
\hline 5. & Elevated and enhanced technological facilities in competitive nations. \\
\hline
\end{tabular}

Extensively adopted marketing methods:

Marketing the area which is progressive and functional in nature and influences everyone. It is a way of providing necessary information about the art works to the consumers. Various activities currently included for making these products available in the market are : A) development of art works B) packaging of artifacts C) pricing and D) dispatching it to the market for private dealers or government dealers or NGO's. Presently the aspect of advertising , sales promotion, branding and sales promotion is lacking for these products. The present efforts of government are insufficient in generating a buzz for these products and the perspective of utilizing the new forms of media for marketing of these art works is lacking. The current system adversely affects the individual product selling opportunity of the artisans because they are always occupied in accessing raw material and generating artifacts for government traders/ NGO's or private traders. Since these artisans are uneducated they lack information about the market and currently existing schemes provided by government for their benefit. This is the reason why they are unable to make use of technological advancements in generating new designs. It is a necessity to make them aware about the important factors of marketing such as product, price , place and promotion.

\section{Product:}

There is a need to stress upon the product development process and provide the necessary technical inputs as required. The raw materials should be made available to the artisans at a minimal price so that the product development cost reduces. These craftsmen should be made aware of the changing patterns and trends and also about the tastes and preferences of the consumers so that they could incorporate the required changes. There are various products that are liked by the consumers from foreign countries but are diminishing from the market due to non availability of raw material and high cost of development so necessary efforts should be taken to revive these products and preserve them. Apart from this there is existence of art works that are less profitable in the product line , these products should be eliminated from the product line.

\section{Price:}

This is one of the vital elements of marketing mix. Factors such as cost of production, demand and competition are considered while deciding the price of these art works. Earlier these artisans used to set the prices of their art works through bargaining with consumers. The craftsmen used to charge higher price for the consumers that they expected would pay higher price but while negotiating they would settle down at an acceptable price for their produce with which the consumers would be satisfied. But in today's scenario the government officials / NGO's or private 
officials purchase these products at a very reasonable rate from the consumers and put their own price tag upon these products which is 20 to fifty times higher than the actual price of these products. This segment is suffering from issues related to pricing because intermediaries play a vital role in fixing the price of these art works. There is a necessity of generating fair strategy of pricing that is appropriate from the point of view of consumers. Also there should be reduction in taxes so that the artisans could earn acceptable wages.

\section{Distribution:}

This process involves transfer of final finished products from producer to final consumer of the product. It includes activities such as transportation of art pieces, storage of art works, legal activities and promotional activities. The distribution medium of these products revolves around intermediaries such as private dealers, government dealers and NGO's since the artisans are not able to sell their art works directly to the final consumers. The current distribution channel is indicated in the figure below:

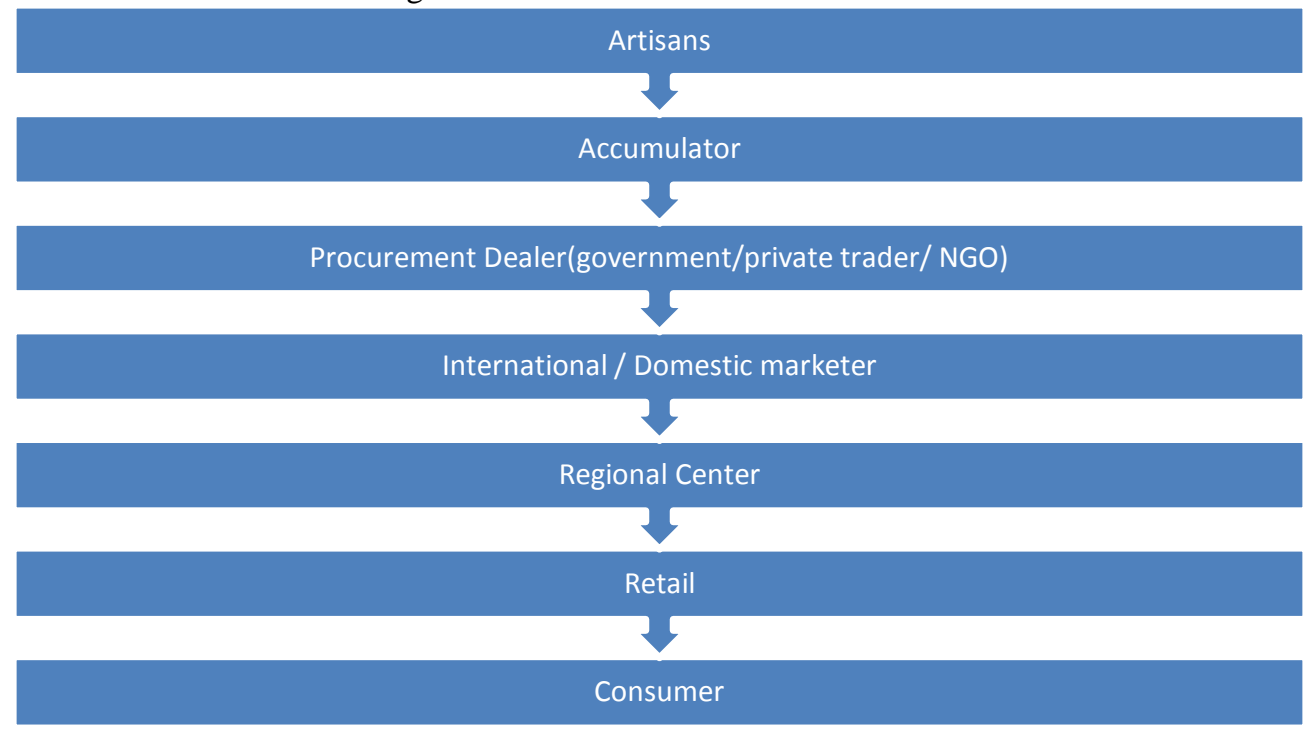

Fig 2:- Representation of current distribution pattern.

\section{Promotion:}

This is another vital aspect of the marketing mix which enables the seller of product to convey the information related to the product to the final consumers. This element helps in developing relation between buyers and sellers. It includes factors such as advertising, packaging, personal selling, publicity etc. The artisans due to lack of education are unaware of strategies of promoting their art works. These craftsmen are not capable of developing the promotional strategies for their products. Hence, there should be efforts made by the private and government organizations for advertising these products and incorporating newer techniques of promotion by utilizing social media marketing, blogging, content marketing etc.

\section{Suggestions:}

1. Advertisement in both domestic and international levels should be considered for continual growth of these Bastar Arts.

2. Increasing the participation of artisans in trade fairs, exhibitions, focusing upon publicity aspect, generation and distribution of brochures that would be beneficial in boosting this art form.

3. It is expected from the government to develop systematic marketing system for these craft works so that the artisans and the customers would be able to avail the benefits . During non appearance of well structured and systematic market both artisans and consumers are exploited.

4. Government should provide tax relaxation for these art works so that the price of these craft works reduces up to a certain level which would result in increased sales of these products.

5. Master artisans from foreign countries should be invited to interact with these artisans and provide necessary guidance to them.

6. Homogeneous pricing is one of the vital factor for growth of these art works. The consumers feel cheated when they witness same art piece available at two different prices at different retail outlets. 


\section{Solutions:}

1. Micro loans for these craft works.

2. Development of houses for raw material .

3. Organizing more sessions for training the artisans.

4. Developing institutions for art works.

5. Competent work force for marketing.

\section{Conclusion:-}

Developing apt strategy of marketing is very vital in present scenario to make these art pieces developed by the tribal artisans more familiar amongst the domestic and international markets with respect to moderate price, looks, design etc. keeping in mind the dynamic time and patterns of marketing. Present day consumers are more technologically savvy, and they prefer to access information easily. The intermediaries in this segment should help the artisans to realize about the present consumption patterns. This segment should continually incorporate innovation in their products so as to meet the needs of end consumers. The prime issues that should be considered are the financial aspect, marketing and production aspect. Artisans should be made aware of the modern ways of marketing as it is crucial for the decision making process by the end consumers. There is a need to focus on advertising in international and domestic platforms. Participation of craftsmen in trade fairs, exhibitions, village haats etc. should be increased and the government should make sure that each and every artisan gets a fair chance to participate in it. There is a need to focus upon the display of products in more and more tourism sites so that it could be accessible to a larger audience. Efforts should be made upon the Research and Development for this segment. Private traders, Government traders and NGO's should also participate in providing these artisans with the required raw materials so that there is a reduction in total cost of production.

\section{References:-}

1. Bastar Folk Art ; Shrines, Figures and Memorials By Michel Postel and Zarine Cooper (pg no. 7-30)

2. Websites : www.bastar.gov.in, www.trifed.in

3. Research paper titled "Marketing challenges of Handicraft retailers in changing environment"written by Dilip Kumar and Rajeev PV ; published in International Journal of Business Management and Economics , Jan 2014 BHU.

4. Jasleen Dharmija,Crafts of Gujrat : Living Traditions of India, Jasleen Dharmija, Mapin International ,National Book Trust, ISBN: 978-8123748818, pp 45-81.

5. Kamaladevi Chattopadhyay,The Glory of Indian Handicrafts , Asia Book Corp of Amer, ISBN: 9780318362687, pp 12-29, 53-70.

6. P.N. Sankaran, Intergenerational Occupational Mobility of Villages of Artisans in Kerela. Artisans of India: Towards inclusive development, Serials Publications, New Delhi, pp 184-195.

7. Harihar Vaishna, Bastar Ki Adivasi Evam Lok Hasthshilp Parampara, Radha Krishna Prakashan,1(1),ISBN: 978-81-8361-676-8, pp 23-50, 87-119,147-173.

8. Verrier Elwin,(1992 June), The Muriya and Their Ghotul,Oxford Univ Pr, ISBN: 978-0195628531,pp 1-39.

9. D.Sharma, Harrappan Terracotta Art, Pratibha Prakashan, ISBN: 978-8177023145, pp 1-15.

10. Lala Jagdalpuri, Bastar Itihaas Evam Sanskriti,Madhya Pradesh Hindi Granth Academy (Bhopal),First Edition,ISBN:8173271836,pp 29-73. 